15

\title{
Экспериментальное определение коэффициента сопротивления конических проникателей и проникателя с плоским передним торцом при сверхзвуковом движении в песчаном грунте
}

\author{
(C) С.И. Герасимов, ${ }^{1,2,3,4}$ В.И. Ерофреев, ${ }^{3,4}$ Ю.Ф. Травов, ${ }^{1}$ А.Г. Иоилев, ${ }^{1}$ В.В. Писецкий, ${ }^{2}$ C.А. Капинос, ${ }^{1}$ \\ А.П. Калмыков, ${ }^{1}$ Н.В. Лапичев ${ }^{1}$ \\ ${ }^{1}$ Российский федеральный ядерный центр - Всероссийский научно-исследовательский институт экспериментальной \\ физики, \\ 607188 Саров, Нижегородская обл., Россия \\ ${ }^{2}$ Саровский физико-технический институт НИЯу МИФИ, \\ 607186 Саров, Нижегородская обл., Россия \\ ${ }^{3}$ Институт проблем машиностроения РАН - фрилиал Института прикладной фризики РАН, \\ 603024 Нижний Новгород, Россия \\ ${ }^{4}$ Нижегородский государственный технический университет им. Р.Е. Алексеева, \\ 603950 Нижний Новгород, Россия \\ e-mail: s.i.gerasimov@mail.ru
}

Поступило в Редакцию 22 июля 2020 г.

В окончательной редакции 14 сентября 2020 г.

Принято к публикации 1 октября 2020 г.

\begin{abstract}
Проведены экспериментальные исследования по определению коэффициента сопротивления при проникании в песчаный грунт конических и цилиндрических ударников. В экспериментах угол полураствора конического наконечника проникателя (ударника) изменялся от 10 до $90 \mathrm{deg}$. Скорость движения ударника изменялась в интервале $0.2-2.0 \mathrm{~km} / \mathrm{s}$. Получены средние значения коэффициента сопротивления для конических тел при квазистационарном сверхзвуковом движении в песчаном грунте средней влажности $7-12 \%$, а для ударников с плоским передним торцом - в песчаном грунте влажностью от 0 до $16 \%$. Показана существенная зависимость коэффициента сопротивления тонких конусов $\left(\beta<25^{\circ}\right)$ от скорости движения и отсутствие таковой (с учетом экспериментальной погрешности) для тупых конусов и ударника с плоским торцом.
\end{abstract}

Ключевые слова: высокоскоростное проникание, конический проникатель, проникатель с плоским передним торцом, песок, коэффициент сопротивления.

DOI: 10.21883/JTF.2021.03.50535.233-20

\section{Введение}

Высокоскоростные проникающие устройства могут применяться для зондирования поверхностного слоя Земли, и в перспективе для других небесных тел с целью изучения их строения и разведки полезных ископаемых [1]. Нагрузки, испытываемые такими устройствами при проникании, не должны приводить к их значительным деформациям, что позволяет рассматривать динамику проникания в грунтовую преграду как движение абсолютно жесткого тела в сопротивляющейся среде [2]. Определение закономерностей процессов проникания твердых тел в грунтовые среды затруднено как нестационарностью самих процессов, так и неоднородностью, нестабильностью свойств природных грунтов. В связи с этим большое значение имеют экспериментальные закономерности, которые применяются для тестирования или верификации применяемых для описания процессов проникания подходов и моделей.

Экспериментальному исследованию процесса проникания в мягкий грунт посвящены сотни публикаций, однако практически все они касаются дозвукового дви- жения. Исследованию же сверхзвукового движения в мягком грунте цилиндрических ударников с коническим наконечником или с плоским передним торцом посвящены немногочисленные работы [3-5].

Нами проведено экспериментальное исследование высокоскоростного процесса проникания металлического ударника в песчаный грунт при скорости движения $V$ в интервале $0.2-2.0 \mathrm{~km} / \mathrm{s}$.

\section{1. Проведение экспериментов}

Для разгона ударников в опытах использовались пушечные ускорители двух типов (рис. 1): пороховые баллистические установки (ПБУ) или двухступенчатая легкогазовая установка (ЛГУ).

Массы метаемых сборок (проникатель плюс поддон или обтюрирующая оболочка, используемые для устойчивого движения в баллистическом стволе) составляли 25-200g при использовании метательных установок с калибром баллистического ствола 14.5 и $23 \mathrm{~mm}$. В опытах на ПБУ калибра $100 \mathrm{~mm}$ масса метаемых сбо- 

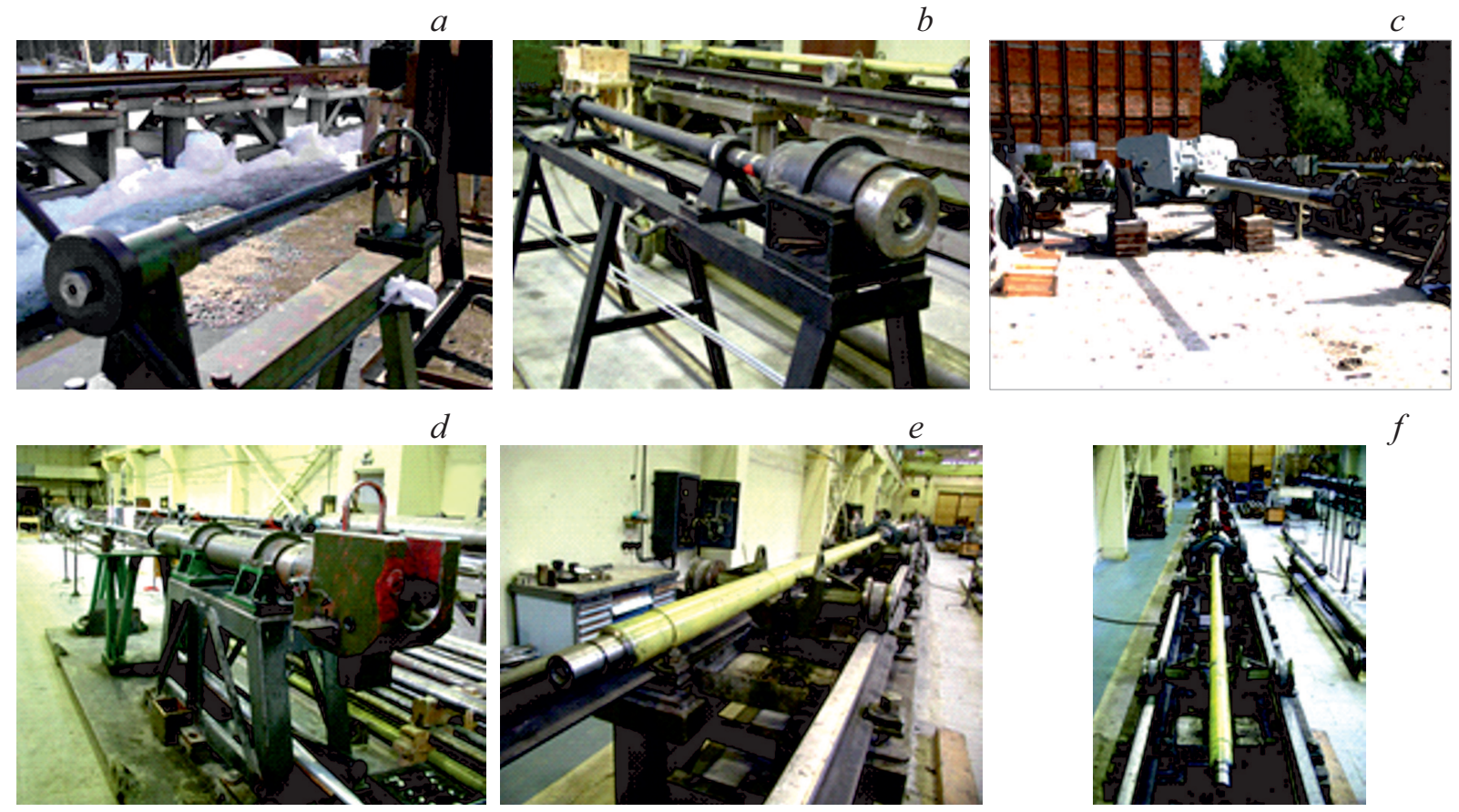

Рис. 1. Метательные установки: $a-$ ПБУ, калибр $14.5 \mathrm{~mm} ; b-$ ПБУ, калибр $23 \mathrm{~mm} ; c-$ ПБУ, калибр $100 \mathrm{~mm} ; d-f-$ ЛГУ, калибр $23 \mathrm{~mm}$.

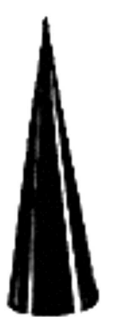

$a$
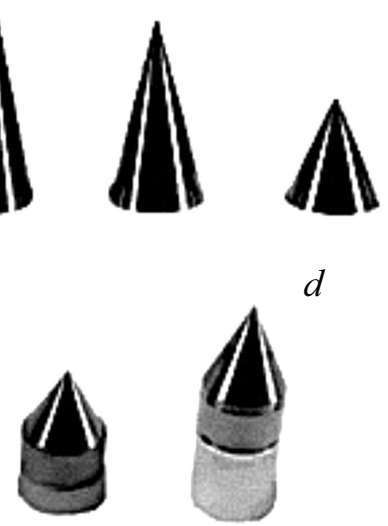

$b$
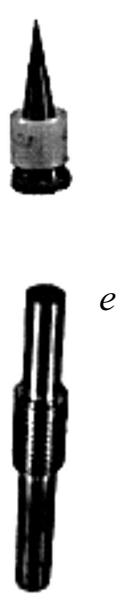
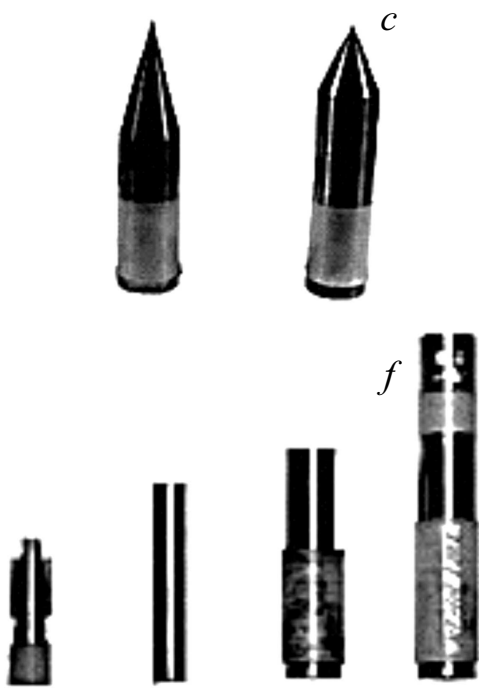

Рис. 2. Проникатели (не в масштабе): $a-$ конус $d=60 \mathrm{~mm}$, слева направо $\beta=10^{\circ}, 15^{\circ}$ и $25^{\circ} ; b-$ конус $d=22 \mathrm{~mm}, \beta=10^{\circ}$; $c$ - цилиндр с коническим наконечником $d=22.5 \mathrm{~mm}$, слева $\beta=15^{\circ}$, справа $\beta=25^{\circ} ; d$ - цилиндр с коническим наконечником $d=22.5 \mathrm{~mm}$, слева $\beta=30^{\circ}$, справа $\beta=25^{\circ} ; e-$ цилиндр $d=10 \mathrm{~mm} ; f$ - цилиндр, слева направо $d=7,10,14.5$ и $22.5 \mathrm{~mm}$.

рок конических проникателей достигала $\sim 2 \mathrm{~kg}$ (конические ударники с углом полураствора $\beta=10,15$ и $25^{\circ}$ ). На рис. 2 приведены фотографии основных типов проникателей с указанием диаметра кавитатора проникателя $d$ и угла $\beta$ (для конических проникателей). Большая часть ударников представляла собой цилиндр с коническим наконечником. Цилиндрическая часть использовалась для увеличения массы и обеспечения условий метания из баллистических устано- вок. Ударники изготовлены из высокопрочной стали ЭП637.

Для определения значения коэффициента сопротивления $C_{x}$ использовались две экспериментальные схемы: 1) хронометрирование процесса проникания в грунтовой среде посредством фиксации времени прохождения заданных сечений с помощью индукционных датчиков [3] или по глубине проникания на фиксированный момент времени срабатывания рентгеновского аппарата [4]; 

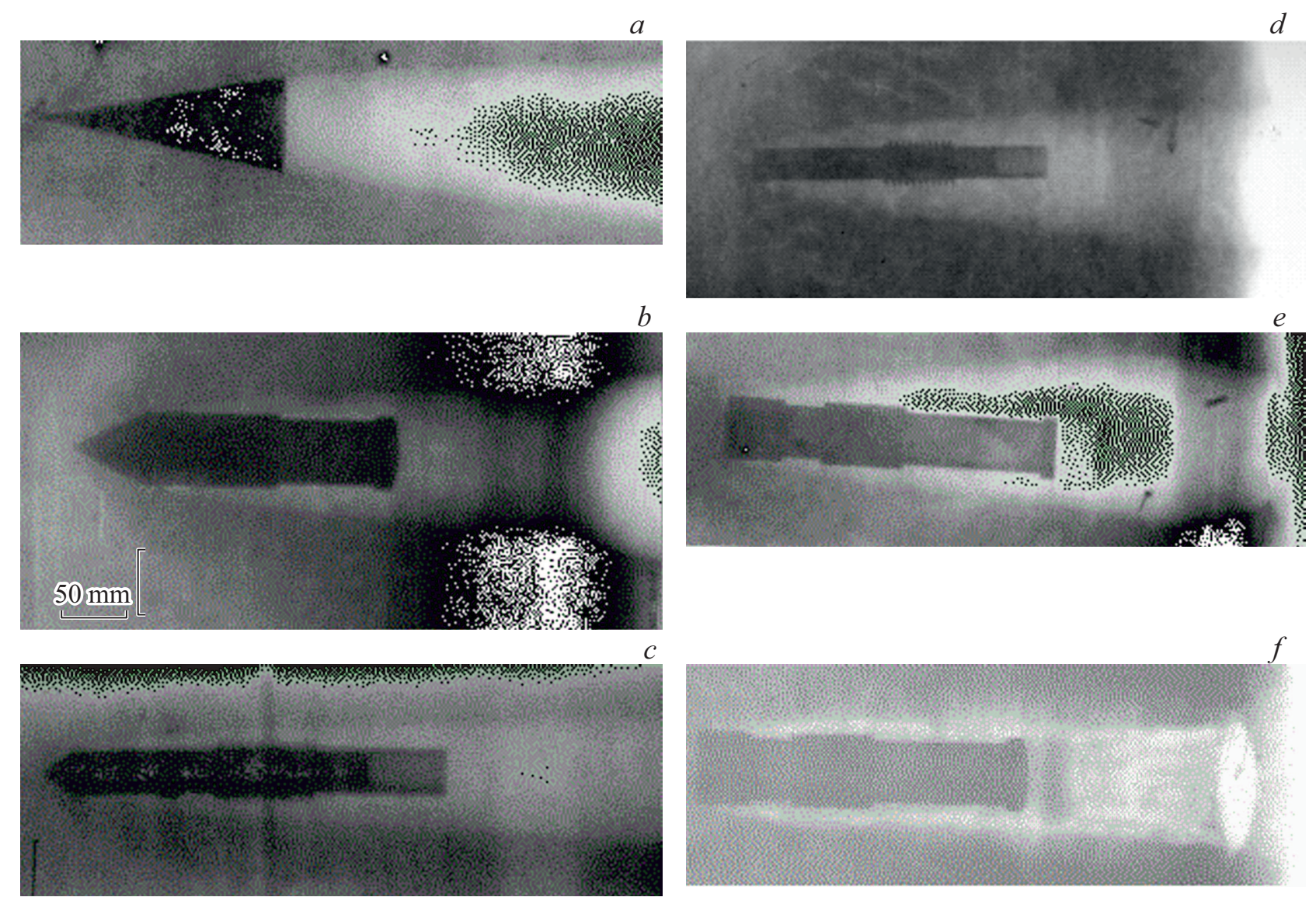

Рис. 3. Характерные рентгенограммы движения ударников в песке (направление движения -справа налево): $a-$ конус $\beta=10^{\circ}$, $m=39 \mathrm{~g}, L=62 \mathrm{~mm}, d=22 \mathrm{~mm}, V_{0}=560 \mathrm{~m} / \mathrm{s}$, грунт-песок с $\rho_{0}=1.73 \mathrm{~g} / \mathrm{cm}^{3}, W=9.3 \% ; b-$ конус $\beta=25^{\circ}, m=203 \mathrm{~g}$, $L=100 \mathrm{~mm}, d=22.5 \mathrm{~mm}, V_{0}=806 \mathrm{~m} / \mathrm{s}$, грунт-песок с $\rho_{0}=1.46 \mathrm{~g} / \mathrm{cm}^{3}, W=0 \% ; c-$ конус $\beta=30^{\circ}, m=52.5 \mathrm{~g}$, $L=90 \mathrm{~mm}, d=10 \mathrm{~mm}, V_{0}=1824 \mathrm{~m} / \mathrm{s}$, грунт-песок с $\rho_{0}=1.57 \mathrm{~g} / \mathrm{cm}^{3}, W=0 \% ; d-$ цилиндр $m=57 \mathrm{~g}, L=90 \mathrm{~mm}$, $d=10 \mathrm{~mm}, V_{0}=1112 \mathrm{~m} / \mathrm{s}$, грунт-песок с $\rho_{0}=1.68 \mathrm{~g} / \mathrm{cm}^{3}, W=8.2 \% ; e$ - цилиндр $m=213 \mathrm{~g}, L=120 \mathrm{~mm}, d=22.5 \mathrm{~mm}$, $V_{0}=401 \mathrm{~m} / \mathrm{s}$, грунт-песок с $\rho_{0}=1.38 \mathrm{~g} / \mathrm{cm}^{3}, W=3 \% ; f$ - цилиндр $m=213 \mathrm{~g}, L=120 \mathrm{~mm}, d=22.5 \mathrm{~mm}, V_{0}=174 \mathrm{~m} / \mathrm{s}$, грунт-песок с $\rho_{0}=1.42 \mathrm{~g} / \mathrm{cm}^{3}, W=0.3 \%$.

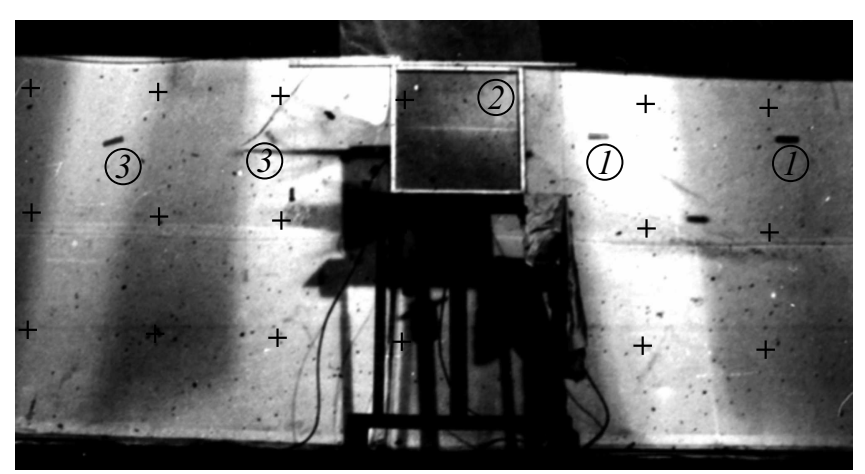

Рис. 4. Аэрофотоснимок пробития контейнера с песком цилиндрическим проникателем: 1 - цилиндрический проникатель перед контейнером, 2 - контейнер, 3 - проникатель после пробития контейнера.

2) регистрация скорости ударника $V_{k}$ после пробития (прострела) преграды известной толщины $\Delta h$.
Для проникателей диаметром $d \leq 22.5 \mathrm{~mm}$ в качестве мишени использовался контейнер с песчаным грунтом, ширина которого составляла $80-100 \mathrm{~mm}$, что позволяло проводить рентгенографирование процесса проникания. В опытах на прострел в случае использования проникателей с $d \leq 23 \mathrm{~mm}$ использовался контейнер диаметром 150-300 mm и длиной от 100 до $300 \mathrm{~mm}$. В опытах с коническими проникателями диаметром $60 \mathrm{~mm}$ использовался контейнер $1 \times 1 \mathrm{~m}$ в поперечном сечении глубиной $\Delta h \approx 400-500 \mathrm{~mm}$.

В опытах с фиксацией времени прохождения с помощью индукционных датчиков в контейнере шириной $100 \mathrm{~mm}$ устанавливалось от трех до семи сечений датчиков на расстоянии от 50 до $150 \mathrm{~mm}$ друг от друга, полная регистрируемая измерительная база составляла 400-500 mm. Чтобы получить полную глубину проникания, в некоторых опытах за контейнером с песком, в котором производилось хронометрирование процесса движения ударника, устанавливался контейнер с песком большего диаметра и длиной до $1 \mathrm{~m}$. 
Во всех опытах угол входа $\theta$ составлял $\sim 90^{\circ}$ от поверхности преграды. На рис. 3 приведены характерные рентгенограммы движения проникателей в песчаном грунте плотностью $\rho_{0}$ и влажностью $W$, указаны скорость удара $V_{0}$, масса $m$ и диаметр $d$ проникателя, a также угол полураствора $\beta$ (для проникателей $\mathrm{c}$ коническим кавитатором).

На рис. 4 приведена фотография характерного опыта на прострел преграды.

\section{2. Результаты и их обсуждение}

При обработке результатов опытов с хронометрированием процесса проникания или с рентгенографированием значение коэффициента сопротивления $C_{x}$ считалось постоянным в скоростном интервале конкретного опыта и рассчитывалось с помощью нелинейной (методом наименьших квадратов) аппроксимации экспериментальных данных путь-время конкретного опыта функцией $h(t)$, полученной интегрированием уравнения движения при постоянном значении $C_{x}$.

Уравнение прямолинейного движения проникателя как жесткого тела:

$$
\frac{d V}{d t}=-C_{x} S_{k}, \frac{\rho_{0} V^{2}}{2 m},
$$

где $m$ и $V$ - масса и скорость проникателя, $S_{k}-$ площадь поперечного сечения его кавитатора, а $\rho_{0}-$ плотность грунта. Интегрирование проводилось в безразмерных переменных

$$
\tilde{h}=h A, \quad \text { и } \tilde{t}=t A V_{0},
$$

где $A=\frac{\rho_{0} S_{k}}{2 m}$, при постоянном коэффициенте сопротивления $C_{x}$ (среднем для интервала глубин от 0 до $\left.h\right)$ :

$$
\tilde{h}(\tilde{t})=\frac{1}{C_{x}} \ln \left(1+C_{x} \tilde{t}\right) .
$$

При обработке результатов опытов на прострел значение $C_{x}$ также считалось постоянным в интервале изменения скорости от $V_{0}$ до $V_{k}$ и относится к среднему значению скорости $V_{a v}=\left(V_{0}+V_{k}\right) / 2$. По известным значениям коэффициента $A$, толщины слоя грунта $\Delta h$, измеренным значениям времени движения проникателя в преграде $t$ и его скорости на входе и выходе $V_{0}$ и выходе из нее $V_{k}$ значение $C_{x}$ вычисляется как

$$
C_{x}=\frac{1}{\Delta h A} \ln \left(\frac{V_{0}}{V_{k}}\right) .
$$

Коэффициент сопротивления $C_{x}$ определялся в каждом опыте, и по количеству опытов с близкими параметрами влажности грунта определялось среднее значение $C_{x}$. Также данные опыты сводились в единую обработку закона движения проникателя с данным углом полураствора конуса. Полученное в опытах на прострел значение $C_{x}$ использовалось для определения времени $t$ достижения ударником глубины $\Delta h$, чтобы использовать этот опыт в совместной обработке закона движения $h_{i}\left(t_{i}\right)$ нескольких опытов с близкими параметрами грунтовой преграды.

Основными параметрами, определяющими погрешность определения $C_{x}$ в опытах, являются:

- точность определения координат заданных сечений в грунте для фиксации прохождения ударника с помощью индукционных либо контактных датчиков, глубины проникания по рентгеновскому снимку, а также толщины пробиваемой преграды;

- точность определения срабатывания датчиков, которая выражается через абсолютную среднеквадратическую погрешность $\Delta t$ (включает погрешность измерительной аппаратуры и неопределенность замыкания датчика, запускающего рентгеновский аппарат, при контакте с моделью).

Абсолютная погрешность координат не превышала $3 \mathrm{~mm}$ на уровне $3 \sigma$ [4-7]. Соответственно среднеквадратическая погрешность не превышала $\sim 1 \mathrm{~mm}$. Среднеквадратическая погрешность регистрации времени срабатывания датчиков составляла $0.4 \mu \mathrm{s}$ [4-7]. Относительная среднеквадратическая погрешность определения скорости удара $V_{0}$ составляет $0.5 \%$. Тем самым максимальная погрешность $\delta$ в определении экспериментального значения $C_{x}$ в конкретном опыте [4,5] с учетом погрешности определения начальной скорости, скорости после пробития преграды, координат заданных сечений в песке, глубины проникания по рентгеновскому снимку, толщины контейнера в опытах на прострел, времени регистрации всех координат движения проникателей оценивается не более $\pm(5-10) \%$.

На основе полученных экспериментальных значений $C_{x}$ в каждом опыте $[4,5]$ определялись средние значения коэффициента сопротивления по всем опытам для каждого угла полураствора конуса в относительно узком интервале влажности песка. В табл. 1 приведены средние значения экспериментальных коэффициентов сопротивления со среднеквадратическим отклонением (СКО) и коэффициентом вариации $v$ по количеству проведенных опытов с близкими параметрами грунта. По большинству всех опытов с коническими проникателями средняя плотность и влажность песка составили $\rho_{0}=1.68 \mathrm{~g} / \mathrm{cm}^{3}$ и $W=9.5 \%$ соответственно. В опытах с коническими проникателями диаметром от 20 до $60 \mathrm{~mm}$ с $\beta=10,15$ и $25^{\circ}$ влияние масштаба на $C_{x}$ не обнаружено.

На рис. 5 приведены экспериментальные значения $C_{x}$, по которым определялось среднее значение для каждого испытанного конического проникателя в относительно узком диапазоне влажности песчаного грунта (табл. 1).

Для проверки возможной зависимости коэффициента сопротивления $C_{x}$ от скорости движения $V$ проведена дополнительная обработка экспериментальных законов движения проникателей $h_{i}\left(t_{i}\right)$, которые аппроксимировались функцией $h(t)$, являющейся решением уравнения движения (1) при трех вариантах функции $C_{x}=C_{x}(V)$ : 
Таблица 1. Коэффициент сопротивления проникателей при движении в песке средней влажности

\begin{tabular}{|c|c|c|c|c|c|c|c|c|c|c|}
\hline \multirow{2}{*}{$\beta$} & \multicolumn{2}{|c|}{$\rho, \mathrm{g} / \mathrm{cm}^{3}$} & \multicolumn{2}{|c|}{$W, \%$} & \multicolumn{2}{|c|}{$V, \mathrm{~m} / \mathrm{s}$} & \multirow{2}{*}{$C_{x}$} & \multirow{2}{*}{ СКО } & \multirow{2}{*}{$v, \%$} & \multirow{2}{*}{$\begin{array}{c}\text { Количество } \\
\text { опытов }\end{array}$} \\
\hline & Интервал & Среднее & Интервал & Среднее & Интервал & Среднее & & & & \\
\hline $10^{\circ}$ & $1.56-1.73$ & 1.68 & $7.0-11.5$ & 9.5 & $\sim 200-1000$ & 630 & 0.300 & 0.076 & 25.3 & 6 \\
\hline $15^{\circ}$ & $1.57-1.70$ & 1.63 & $7.4-11.2$ & 8.8 & $\sim 500-950$ & 675 & 0.379 & 0.034 & 9.0 & 4 \\
\hline $25^{\circ}$ & $1.51-1.76$ & 1.66 & $7.2-11.4$ & 8.4 & $\sim 300-2100$ & 770 & 0.764 & 0.034 & 4.4 & 13 \\
\hline $30^{\circ}$ & $1.59-1.70$ & 1.68 & $6.5-8.0$ & 6.8 & $\sim 350-2200$ & 1300 & 0.881 & 0.046 & 5.3 & 5 \\
\hline $45^{\circ}$ & $1.67-1.78$ & 1.72 & $10-12.5$ & 11.4 & $\sim 300-800$ & 550 & 0.960 & 0.021 & 2.2 & 4 \\
\hline $60^{\circ}$ & $1.64-1.78$ & 1.69 & $11-12.0$ & 11.7 & $\sim 350-800$ & 575 & 1.134 & 0.053 & 4.7 & 3 \\
\hline $75^{\circ}$ & $1.64-1.73$ & 1.69 & $9.0-11.0$ & 10.0 & $\sim 350-800$ & 575 & 1.355 & 0.063 & 4.6 & 3 \\
\hline $90^{\circ}$ & $1.58-1.72$ & 1.69 & $7.6-11.0$ & 9.5 & $\sim 300-1100$ & 700 & 1.559 & 0.058 & 3.7 & 9 \\
\hline
\end{tabular}

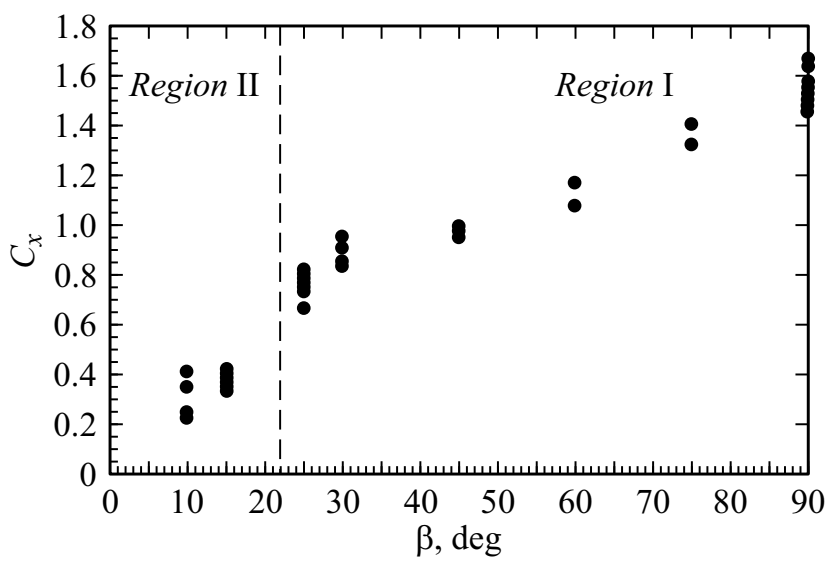

Рис. 5. Зависимость экспериментального коэффициента сопротивления от угла полураствора конического наконечника.

Первый вариант функции $C_{x}=C_{x}(V)$ :

$$
C_{x}=\text { const. }
$$

В этом случае используется решение (3). По экспериментальным данным методом наименьших квадратов подбирается коэффициент аппроксимации $C_{x}$.

Второй вариант функции $C_{x}=C_{x}(V)$ :

$$
C_{x}(M)=b M^{\gamma},
$$

где $M=V / a_{0}$ - число Маха $\left(a_{0}-\right.$ скорость звука в песке), а $b=C_{x}(M \rightarrow 1)(M=1-$ нижняя граница рассматриваемого нами диапазона скоростей проникания в песок). По экспериментальным данным методом наименьших квадратов подбираются коэффициенты аппроксимации $b$ и $\gamma$. В этом случае зависимость безразмерной глубины проникания от безразмерного времени следующая:

$$
\tilde{h}(\tilde{t})=\frac{1}{b \gamma} M^{\gamma} .
$$

Значение скорости звука в песке (в $\mathrm{km} / \mathrm{s})$ рассчитывается по эмпирической зависимости [8]

$$
A_{0}=0.28\left(\frac{\alpha_{10}}{\alpha_{10}+\alpha_{20}}\right)^{-0.54}
$$

через значения объемных долей воздуха $\alpha_{10}$ и воды $\alpha_{20}$, которые вычисляются по измеренным перед опытом значениям плотности $\rho_{0}$ и влажности $W$ грунта как [8]

$$
\begin{aligned}
& \alpha_{20}=\frac{\rho_{0} W}{(1+W) \rho_{20}}, \alpha_{30}=\frac{\rho_{0}}{(1+W) \rho_{30}}, \\
& \alpha_{10}=1-\left(\alpha_{20}+\alpha_{30}\right) .
\end{aligned}
$$

Песчаный грунт рассматривается как трехкомпонентная среда с начальной плотностью $\rho_{0}$ и влажностью $W$ :

$$
\rho_{0}=\alpha_{10} \rho_{10}+\alpha_{20} \rho_{20}+\alpha_{30} \rho_{30} .
$$

Плотность твердого компонента (кварц) $\rho_{30}=2.65 \mathrm{~g} / \mathrm{cm}^{3}$, жидкого (вода) $\rho_{20}=1.0 \mathrm{~g} / \mathrm{cm}^{3}$.

Третий вариант функции $C_{x}=C_{x}(V)$ :

$$
C_{x}(V)=C_{0}+2 H_{d} /\left(\rho_{0} V^{2}\right),
$$

где $C_{0}=C_{x}(V \rightarrow \infty), H_{d}-$ прочность преграды, используемая в записи силы сопротивления в форме Понселе [3]. По экспериментальным данным методом наименьших квадратов подбираются коэффициенты аппроксимации $C_{0}$ и $H_{d}$. В этом случае зависимость безразмерной глубины проникания от безразмерного времени следующая:

$$
\begin{aligned}
\tilde{h}(\tilde{t}) & =\frac{1}{C_{0}} \ln \mid \cos \left(\tilde{t} \sqrt{\frac{2 C_{0} H_{d}}{\rho_{0} V_{0}^{2}}}\right) \\
& +\sqrt{\frac{C_{0} \rho_{0} V_{0}}{2 H_{d}}} \sin \left(\tilde{t} \sqrt{\frac{2 C_{0} H_{d}}{\rho_{0} V_{0}^{2}}}\right) \mid .
\end{aligned}
$$

В табл. 2 представлены результаты обработки экспериментальных данных закона движения $h_{i}\left(t_{i}\right)$ по нескольким опытам для каждого исследованного типа проникателей для трех вариантов зависимости $C_{x}$ от скорости движения.

Полученные значения показателей степени аппроксимации $\gamma$ показывают, что для конических проникателей с $\beta=10^{\circ}$ и $15^{\text {circ }}$ коэффициент сопротивления заметно растет с уменьшением скорости. Для проникателей с более тупым $\left(\beta \geq 25^{\circ}\right)$ коническим кавитатором и для 
Таблица 2. Коэффициент сопротивления проникателей при разной скорости движения в песке

\begin{tabular}{|c|c|c|c|c|c|c|c|c|}
\hline \multirow[b]{2}{*}{$\beta$} & \multirow{2}{*}{$\begin{array}{c}\text { Интервал } \\
\text { скорости } \\
\text { проникания }\end{array}$} & \multirow{2}{*}{$\begin{array}{c}\text { Интервал } \\
\text { плотности } \\
\rho_{0}, \mathrm{~g} / \mathrm{cm}^{3}\end{array}$} & \multirow{2}{*}{$\begin{array}{c}\text { Интервал } \\
\text { влажности } \\
W, \%\end{array}$} & \multirow[b]{2}{*}{$C_{x}=$ const } & \multicolumn{2}{|c|}{$C_{x}=b M^{\gamma}$} & \multicolumn{2}{|c|}{$C_{x}=C_{0} 2 H_{d} / \rho_{0} V^{2}$} \\
\hline & & & & & $\begin{array}{c}b \\
\left(a_{0}, \mathrm{~m} / \mathrm{s}\right)\end{array}$ & $\gamma$ & $C_{0}$ & $\begin{array}{c}H_{d}, \\
\mathrm{MPa}\end{array}$ \\
\hline $10^{\circ}$ & $300-1000$ & $1.56-1.73$ & $7.0-11.5$ & 0.376 & $0.512(261)$ & 0.622 & 0.189 & 30.0 \\
\hline $15^{\circ}$ & $500-950$ & $1.57-1.70$ & $7.5-11.2$ & 0.354 & $0.569(253)$ & 0.403 & 0.293 & 31.9 \\
\hline $25^{\circ}$ & $250-2100$ & $1.51-1.73$ & $7.2-11.4$ & 0.784 & $0.800(253)$ & 0.026 & 0.769 & 2.0 \\
\hline $30^{\circ}$ & $400-2100$ & $1.59-1.70$ & $6.5-8.0$ & 0.869 & $0.875(245)$ & 0.004 & 0.854 & 13.0 \\
\hline $45^{\circ}$ & $300-800$ & $1.67-1.78$ & $10.0-12.5$ & 0.956 & $0.999(280)$ & 0.06 & 0.948 & 7.6 \\
\hline $60^{\circ}$ & $400-800$ & $1.64-1.78$ & $11-12$ & 1.113 & $1.122(277)$ & 0.01 & 1.102 & 6.5 \\
\hline $75^{\circ}$ & $300-800$ & $1.64-1.73$ & $9-11$ & 1.354 & $1.360(265)$ & 0.007 & 1.289 & 7.8 \\
\hline \multirow{3}{*}{$90^{\circ}$} & $200-1000$ & $1.33-1.66$ & $0-0.6$ & 2.558 & $2.606(208)$ & 0.017 & 2.278 & 9.5 \\
\hline & $250-1200$ & $1.58-1.75$ & $7.6-11.0$ & 1.510 & $1.561(262)$ & 0.036 & 1.504 & 18.9 \\
\hline & $250-900$ & $1.62-1.86$ & $11.4-16.7$ & 1.398 & $1.439(313)$ & 0.062 & 1.346 & 8.6 \\
\hline
\end{tabular}

проникателей с плоским передним торцом $\left(\beta=90^{\circ}\right)$, зависимостью $C_{x}$ от $V$ можно пренебречь: в исследованном диапазоне скоростей проникания $\gamma \approx 0$ в пределах экспериментальной погрешности $[4,5]$. Отсутствие зависимости коэффициента сопротивления проникателя от его скорости можно считать справедливым только для исследованного интервала скоростей проникания $\left(0.2 \leq V_{0} \leq 2.0\right) \mathrm{km} / \mathrm{s}$. Для песчаного грунта этот скоростной диапазон соответствует сверхзвуковому движению. При уменьшении скорости движения (в случае песка - дозвуковой режим) наблюдается существенное увеличение значения $C_{x}$ (см., например, $[3,9]$ ).

На рис. 5 можно выделить две характерные области значений угла полураствора конического наконечника $\beta$ из всего диапазона углов полураствора $\left(0<\beta \leq 90^{\circ}\right)$, границей раздела этих областей будем считать угол $\beta=\beta_{* *}$ проникателя, перед которым формируется отошедшая головная ударная волна (УВ): при $\beta_{* *} \leq \beta \leq 90^{\circ}$ (область I на рис. 5, движение с отошедшей УВ) зависимостью коэффициента сопротивления от скорости проникания можно пренебрегать, а при $0<\beta<\beta_{* *}$ (область II на рис. 5, движение с присоединенной УВ) необходимо учитывать зависимость коэффициента сопротивления от скорости движения (числа Маха). Значение угла $\beta_{* *}$ определяется по эмпирической зависимости [10]

$$
\beta_{* *}=\arcsin \left[(\lambda / 1.6)^{5 / 9}\right],
$$

причем коэффициент относительного сжатия $\lambda$ трехкомпонентной среды в первом приближении можно принять равным объемному содержанию воздуха в песке: $\lambda \approx \alpha_{10}$.

На рис. 5 отмечено значение угла $\beta_{* *}=22^{\circ}$, вычисленное по формулам (13) и (9) для средних в опытах с коническими проникателями значений плотности и влажности грунта $\rho_{0}=1.68 \mathrm{~g} / \mathrm{cm}^{3}$ и $W=9.5 \%$ $(\lambda \approx 0.275)$.

На рис. 6-9 приведены экспериментальные значения $C_{x}$, полученные в конкретных опытах для сред-

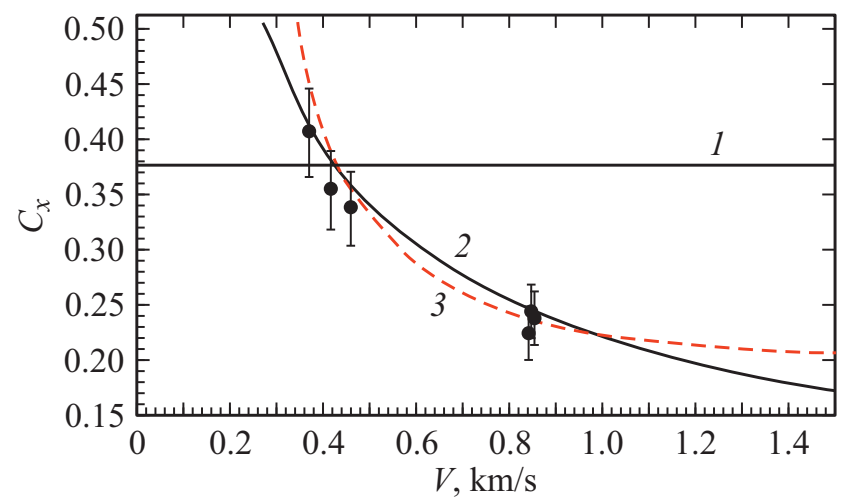

Рис. 6. Зависимость $C_{x}$ от скорости проникания конуса $\beta=10^{\circ}: \bullet-$ эксперимент (разброс $\delta= \pm 10 \%) ; \quad 1-C_{x}=$ const; $2-C_{x}(M)=b M^{-\gamma}$; $3-C_{x}(V)=C_{0}+2 H_{d} /\left(\rho_{0} V^{2}\right)$.

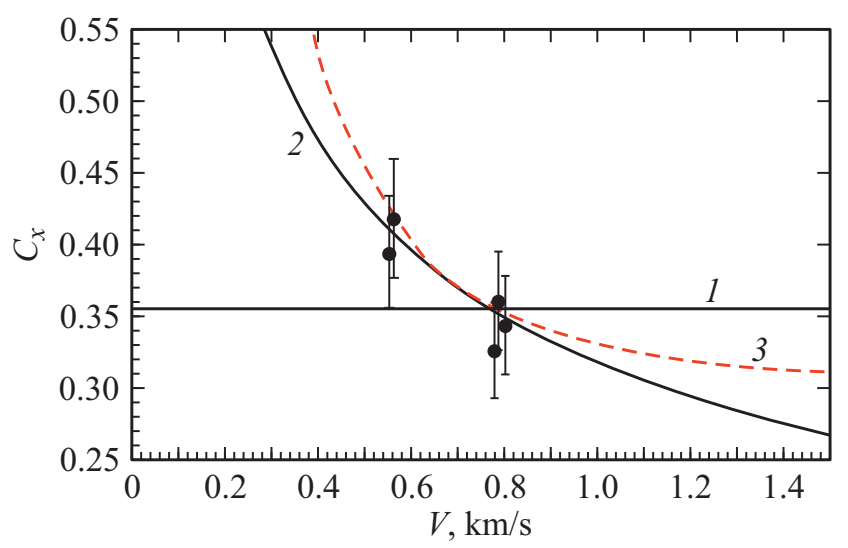

Рис. 7. Зависимость $C_{x}$ от скорости проникания конуса $\beta=15^{\circ}$ : $\quad$-эксперимент (разброс $\delta= \pm 10 \%) ; \quad 1-C_{x}=$ const; $2-C_{x}(M)=b^{-\gamma}$; $3-C_{x}(V)=C_{0}+2 H_{d} /\left(\rho_{0} V^{2}\right)$.

ней скорости движения проникателя, и графики аппроксимационных зависимостей $C_{x}(V)$ для четырех уг- 


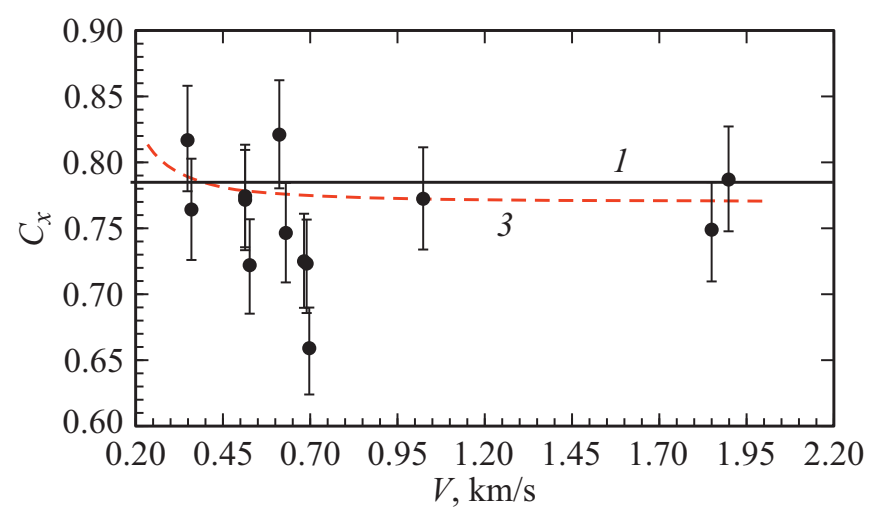

Pис. 8. Зависимость $C_{x}$ от скорости проникания конуса $\beta=25^{\circ}: \bullet-$-эксперимент (разброс $\delta= \pm 5 \%$ ); $1-C_{x}=$ const; $3-C_{x}(V)=C_{0}+2 H_{d} /\left(\rho_{0} V^{2}\right)$.

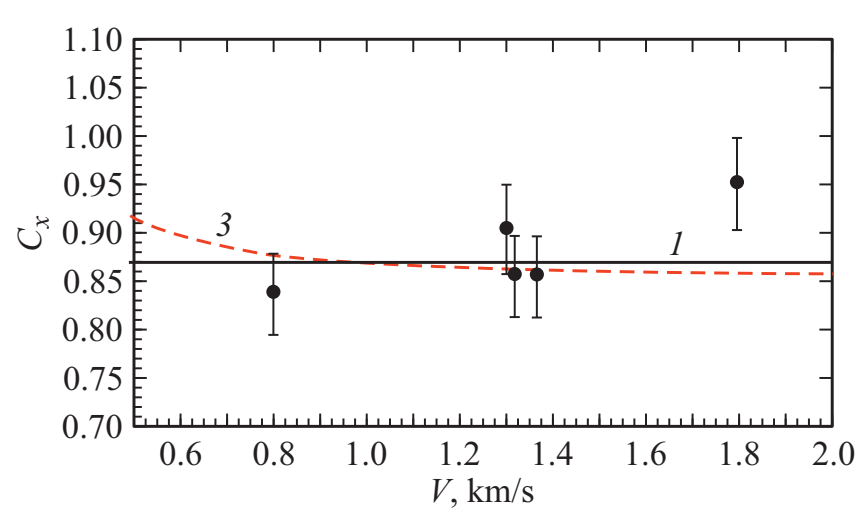

Рис. 9. Зависимость $C_{x}$ от скорости проникания конуса $\beta=30^{\circ}:-\quad-\quad$ эксперимент (разброс $\delta= \pm 5 \%$ ); $1-C_{x}=$ const; $3-C_{x}(V)=C_{0}+2 H_{d} /\left(\rho_{0} V^{2}\right)$.

лов полураствора конического наконечника проникателя: $\beta=10,15,25$ и $30^{\circ}$ соответственно. Зависимости $C_{x}(V)$ определялись аппроксимацией экспериментальных значений $h_{i}\left(t_{i}\right)$ по всем опытам с проникателями одного угла полураствора конического наконечника, значения параметров аппроксимаций $C_{x}(V)$ приведены в табл. 2. Видно, что при $\beta=10$ и $15^{\circ}$ коэффициент сопротивления существенно зависит от скорости движения, а при $\beta=25$ и $30^{\circ}-$ практически не зависит.

\section{Заключение}

Таким образом, анализ результатов экспериментов по определению коэффициента сопротивления $C_{x}$ конических и цилиндрических ударников (всего восемь типов ударников) при проникании в песчаный грунт (для конических ударников - в песчаный грунт средней влажности $W=7-12 \%$, для ударника с плоским передним торцом - в песчаный грунт влажностью W от 0 до 16\%) выявил (при экспериментальной погрешности не более $\pm 10 \%$ ) существенную зависимость $C_{x}$ от скорости проникания $V$ только для острых конусов (угол полураствора $\beta<25^{\circ}$ ) и отсутствие таковой для тупых конусов $\left(\beta \geq 25^{\circ}\right)$ и ударника с передним плоским торцом $\left(\beta=90^{\circ}\right)$. Скорость ударника $V$ изменялась в интервале $(0.2-2.0) \mathrm{km} / \mathrm{s}$, что соответствует сверхзвуковому движению в песчаном грунте.

\section{Конфликт интересов}

Авторы заявляют, что у них нет конфликта интересов.

\section{Список литературы}

[1] В.А. Велданов, В.Е. Смирнов, О.Б. Хаврошкин. Астрономический вестник, 33 (5), 490 (1999).

[2] В.А. Велданов, С.В. Федоров. Прикладная механика и техническая физика, 46 (6), 116 (2005).

[3] У. Аллен, Э. Мейфилд, Г. Моррисон. Сборник переводов „Механика“, 6, 125 (1957).

[4] В.А. Бердников, Ю.Ф. Травов, Г.Ф. Копытов, М.В. Каминский, В.А. Могилев, Ю.И. Файков, Ю.А. Фатеев. Экспериментальное исследование движения конусов и цилиндра в песчаной среде. Сборник материалов II научной конференции РАРАН „Современные методы проектирования и отработки ракетно-артиллерийского вооружения“(РФЯЦ-ВНИИЭФ, Саров, 2002), с. 276.

[5] А.М. Близнюк, Г.Ф. Копытов, Ю.В. Кочнев. Известия Российской Академии ракетных и артиллерийских наук, 4 (49), 34 (2006).

[6] А.В. Зубанков, С.И. Герасимов. Приборы и Техника Эксперимента, 3, 30 (2019).

[7] С.И. Герасимов, Д.В. Захаров, А.В. Зубанков, В.А. Кикеев, Е.С. Хорошайло. Научная визуализация, 10 (2), 1 (2018).

[8] Л.С. Евтерев, Б.В. Замышляев. Модели динамического деформирования и разрушения грунтовых сред (Наука, M, 1990)

[9] Ю.Н. Бухарев, В.П. Гандурин. Анализ сил, действующих на ударники с конической, полусферической и плоской носовыми частями в нестационарной стадии внедрения в воду и грунт / Прикладные задачи высокоскоростного удара. Под ред. Ю.Н. Бухарева. (РФЯЦВНИИЭФ, Саров, 2011), С. 155-170.

[10] У.Д. Хейз, Р.Ф. Пробстин. Теория гиперзвуковых течений (ИЛ, М, 1962) 